\title{
Motivators of Participation and Non- Participation in Youth Environmental Protests
}

\author{
Hannah R. Feldman* \\ Australian National Centre for the Public Awareness of Science, Australian National University, Canberra, ACT, Australia
}

This paper is an exploratory study investigating motivators of teenagers to both attend and not attend a climate change related protest event. Using open-ended surveys and focus groups, 16-19-year-old Australian students were asked about their motivators to attend and abstain from Schoo/ Strike 4 Climate events. Through qualitative analysis and thematic coding, results show key motivators to attend a Strike include climate change and acts of political participation that provide youth with a public voice. Protest is positioned as a key part of teen political repertoires. Reasons for non-attendance included prioritizing schoolwork and low efficacy in protest or participatory action. However, low efficacy in climate change mitigation, or an outright rejection of climate science, was not evident in this sample. Overall, reasons for attendance and non-attendance at a Strike event were not direct mirror images of the other, and implications for inclusion of non-participants in further studies is discussed in this light.

Edited by:

Sarah E. Pickard,

Université de la Sorbonne Nouvelle

Paris III, France

Reviewed by: Carla Malafaia,

University of Porto, Portugal Joost De Moor Stockholm University, Sweden

*Correspondence: Hannah R. Feldman Hannah.feldman@anu.edu.au

Specialty section: This article was submitted to

Political Participation,

a section of the journal

Frontiers in Political Science

Received: 01 February 2021

Accepted: 05 May 2021 Published: 10 September 2021

Citation:

Feldman HR (2021) Motivators of Participation and Non-Participation in

Youth Environmental Protests.

Front. Polit. Sci. 3:662687.

doi: 10.3389/fpos.2021.662687
Keywords: youth, climate strike, fridays for future, school strike for climate, Australia, youth activism, protest mobilization, protest motivation

\section{INTRODUCTION AND LITERATURE}

\section{Introduction and Contribution}

This paper explores young people's motivations to attend or not attend an environmental activism event. Through surveys and focus groups with 15-19-year-old Australian students, this research provides an exploratory introduction to how teenagers discuss their decisions to not participate in a School Strike four Climate event, as well as contributing further examples on their motivations to participate. This research engages with teenagers directly, qualitatively analyzing open ended questions where young people report reasons for both attending and not attending a Strike. The findings form the basis for exploratory work into the motivators of Strike participation and abstention in late-teens, a chronically under-researched age group in political studies, and contribute to the broader picture of youth environmental activism with students who both attend or not attend School Strike events.

\section{Social Movements and the School Strike}

The School Strike 4 Climate (otherwise known as Fridays for Future, Climate Strike or Skolstrejk för Klimatet) is a growing movement of young people leaving school-going on strike-to protest government inaction on climate change. Started by then-16-year-old Greta Thunberg, the movement has swelled to millions of participants across 125 countries, and continues to operate even under crippling COVID-19 pandemic conditions. But research on the motivations of these young people to participate in a Strike is scarce. 
To begin our exploration of these Strikes, we look first to extensive literature on factors that motivate people to attend collective action events. Klandermans and Oegema (1987) contribute the model of "Mobilization Potential" (p. 519), exploring elements that must align for protest participation: people must hear about the event, sympathize with both the aims and format of the event, be motivated to attend, and also be enabled to attend (van Stekelenburg and Klandermans, 2013).

Further, van Zomeren et al. (2008) contribute a comprehensive model for exploring the effects of social identity in collective action. The Social Identity Model of Collective Action (SIMCA) is an integrated model of three key socio-psychological predictors for collective action: injustice, efficacy and identity (van Zomeren et al., 2008). This model has been used by scholars to delve deeper into motivators of young School Strike attendees. For example, Brügger et al. (2020) integrate the SIMCA to explore Strike motivations of over 4,000 Swiss youth aged 14-25. Their study found that social identity (the extent to which participants associate with other Strikers) as well as students risk perception of climate change were key factors in predicting engagement with the School Strike movement.

In exploration of the School Strike, a range of these factors from mobilization potential to social identity may be useful in not only investigating how young people come to attend or discuss protest events, but also how they may fall out of the participation pool, highlighting factors that could contribute to their nonattendance.

\section{Youth Attendance at a Strike Event}

While it may be difficult to assess young people's level of climate change engagement (Partridge, 2008), they have been found on numerous occasions to be knowledgeable about climate (Lee et al., 2020), concerned (Bentley et al., 2004), and emotional about (Ojala, 2012) the realities of climate change. The Strikes have been shown to connect deeply with young people's climate anxieties (McKnight, 2020), reflecting young people's negative and pessimistic experiences with climate change (Han and Ahn, 2020).

However, it has become a common trope that young people are 'politically disengaged' from civic life (Harris, et al., 2010). Despite this misconception, young people are instead well known to be politically active in ways that deviate from classical views of 'political engagement' (Norris, 2003; Pickard, 2019). While 'political behaviors' in the past have been centered around engagement with formal structures of government such as knowledge of polity processes, or participating in political campaigning (Delli and Michael, 2000), young people today are much more likely to be issues-focused in their political engagement (Pickard and Bessant, 2018). This means that political behaviors to young people may instead constitute a repertoire of signing petitions, consumer politics such as boycotting brands, and protesting.

Via the School Strike movement, young people are using political action to voice their concern for their futures and the environment (McKnight, 2020), which pushes back against the picture of a passive youth citizen, despite politics often being 'done to' young people rather than actively including them (Fyfe,
2009; Andersson, 2015). These Strikes distinctly focus on governmental entities or the "State" (de Moor et al., 2020a, p. 4) as important actors in mitigation of climate change, which appears at odds with prior research investigating youth locus of control in environmental care. As an example, Fielding and Head (2012) found that, among Australians aged 18-24 years, a view that 'governments are responsible for protecting the environment' related significantly to lower levels of proenvironmental behavior. A similar (but not significant) relationship was apparent for 12-17-year-old's (Fielding and Head, 2012). This poses an interesting contrast for researchers of the School Strike. While the refocus to the state does not equate to faith in political institutions to solve the climate crisis (de Moor et al., 2020a) there exists an opportunity here to build on existing findings where youth are imploring governments to take greater responsibility for environmental management.

Research with participants of this fast growing movement, however, can be challenging, and few studies have been able to engage directly with young people to explore how and why the School Strike movement has become what we see today. Sources such as editorials, speeches, interviews and other public domain material from youth Strike participants have been used to explore narratives in School Strike discourse, particularly that of influential Greta Thunberg (Han and Ahn, 2020). Similarly, for example, letters written by United States students to the office of the President demanding climate action have also been used to explore the movement (Zummo et al., 2020). Broadly, three key themes emerged from the writings: solution-oriented discourse, which included positive affirmations of community and government level climate mitigations; climate politics discourse, including advocacy for policy-based solutions and anti-capitalist themes; and discourse of doom, and the impacts of climate change on humans and animals (Zummo et al., 2020).

Large scale surveys of climate strike participants (Wahlström et al., 2019; de Moor et al., 2020b) provide the most comprehensive investigations to date on young Strike participants and their protest motivations. Specifically relevant to this study, Collin et al. (2020) contribute to de Moor et al. (2020b) by surveying participants at the Sydney, Australia, School Strike in September 2019. Participants were invited to select (from a number of pre-set responses) what their motivations for participation were, where the most likely reported reason to attend was to pressure political institutions on climate change action (Collin et al., 2020). This was followed by expressions of solidarity with the movement, and social factors such as someone asking them to join were reported least likely. 10-15-year-old attendees in this study were asked to describe in their own words their reasons for attending (Collin et al., 2020): In addition to reporting sentiments of pressuring governments, they also worry about their futures, and this is consistent with other research in this area that has examined narratives of anxiety in the way young people discuss the Climate Strike (McKnight, 2020).

Further exploring young citizens motivations of School Strike participation can help us to better understand how these intersections of climate change and political action converge for young citizens. 


\section{Youth Non-Attendance at a Strike Event}

Much School Strike research to date has understandably centered on the motivators for student participation. However, nonparticipation at an event does not necessarily signify a nonengaged or apathetic student. Active non-participation in political activity (such as abstaining, or boycotting an event) is a distinct response from apathy or forced non-participation (Harris et al., 2010), and understanding this behavior is key to understanding the broader socio-cultural context surrounding the School Strike movement.

Reasons for non-participation can in some cases be directly linked to reasons for participation. For example, Klandermans and Van Stekelenburg, (2014) posit that non-participation can be the result of falling out of a protest mobilization potential pool. That is, despite sympathizing with a movement, some people may simply not be motivated to engage further, may not hear about an event, or simply be unable to attend (Klandermans and Van Stekelenburg, 2014).

Efficacy (or a lack thereof) can also be key to non-participation (van Stekelenburg and Klandermans, 2013), and this can include the perceived effectiveness of the protest event itself. Perceived effectiveness here refers to a wide range of outcomes, from capacity to influence political process through to achievement of specific demands or goals of a protest group (Hornsey et al., 2006). Hornsey at al. (2006) further propose that perceived effectiveness of a movement may also incorporate broader societal or individual goals, including recruitment of more participants to a cause, influencing third parties (outside of the protestors and their oppositional group), and also to use the collective action as an avenue for expressing one's personal values and feelings on an issue.

Often, understanding of non-participation is inferred via research of protest attendees and their motivations to participate, rather than direct exploration of non-participation as an active choice. Stuart et al. (2018) present an exception to this participant-focused bias, surveying 112 Australians (mean age 32) that were sympathetic to a cause, but did not participate in collective action. In this study, the authors looked into "negative protester stereotypes, social incentives, identity performances, and autonomy needs, and the ways in which they inform social identity development and participative efficacy" (Stuart et al., 2018, p. 260). They found that "motivated inaction" (Stuart et al., 2018 , p. 245) stemmed most commonly from: a misalignment between support for a cause but little support for methods of activism (such as protesting); rejection of being socially associated with extreme activists; concern about loss of autonomy and individual impact on individual efforts when becoming part of a larger group. These active reasons highlight that nonparticipation is not necessarily as simple as being the 'opposite' of participation (Klandermans and Van Stekelenburg, 2014), and other factors such as engagement with social norms (how likely your social environment is to enable or discourage participation) can also play a role in decisions to not participate in collective action (Klandermans and Van Stekelenburg, 2014).

Aside from internal drivers of non-participation, barriers or reluctance to engage with activism such as the School Strike may be reflective of the adult power in young people's lives, including the political, educational and familial structures within which young people operate. Youth are often dismissed as inexperienced in adult-driven political systems, therefore unable to reliably engage with its structures (Bessant, 2020). Young people participating in the School Strike movement are no different, heavily criticized on their inexperience with climate policy (Feldman, 2020) and therefore their ability to engage with issues brought about by the movement. It is no wonder, therefore, that young people are often pessimistic about their ability to make change in political systems, and can have low confidence in specific political repertoires such as protest events (Manning and Ryan, 2004).

In general, Australian students see themselves as politically engaged, but have repeatedly reported low political self-efficacy (Collin, 2008). Since political efficacy can act as a strong predictor of civic action (Solhaug, 2006), exclusion from adult-dominated spaces may be contributing to their disengagement from movements such as the School Strike. One example of this exclusion is a lack of youth representation in government, which may lead to distrust and ultimately disengagement from the system (Manning and Edwards, 2014). Manning and Ryan (2004) conducted an Australian study of 13-25-year-olds, through 755 surveys and a number of focus groups, reporting low efficacy in certain forms of political participation, including protesting. When asked what may increase this efficacy, young people reported that meaningful consultation with adults (through youth advisory councils and similar) would be a promising pathway to more meaningful and impactful engagement with polity (Manning and Ryan, 2004), suggesting that current access points for young people are lacking in impact. Given that political engagement and experience is still seen as a top-down transfer of knowledge from adults to youth (Andersson, 2015; Feldman, 2020), this exclusion from climate politics may be pushing young people away from engaging with the School Strike.

Other adult influences may include those of parents and families, as parents play a considerable role in the socialization of young people (Dalton, 1982). Practical barriers such as transport to an event or not hearing of an event may also play into non-participation (van Stekelenburg and Klandermans, 2013) and this may especially be the case where teenagers rely strongly on parents to help them with transportation. Finally, school communities are also administered by adults in positions of power. Young people may also be disengaging in favor of other priorities, such as work or school life (Harris et al., 2010), and these too may be a reflection of other structural pressures on their lives.

While large numbers of global students have been turning out for School Strike events, studies focusing on participants may miss the critical barriers or decision making that results in nonparticipation, an equally crucial part of the School Strike or broader youth activism narrative. As outlined by this literature, while there are similarities in reasons for both attendance and non-attendance, one is not a direct reflection of the other (see also Klandermans and Van Stekelenburg, 2014). This research contributes the first exploratory research into why 
TABLE 1 | Prompts given in each stage of data collection.

\section{Prompt}

Have you attended a Climate Strike event?

What was your main reason for attending/not attending a Climate Strike event?

Why do you think people attend/not attend a Climate Strike event? Your own reasons or reasons of others.

Much media has stated that students attend School Strike events in order to get a day off school. Could you reflect on this

statement, and tell me what you think about it?

\section{Data collection tool}

Pilot survey, full survey, focus groups Pilot survey, full survey

Focus groups

Focus groups young Australians may deliberately not be participating in a School Strike event.

\section{METHODS}

\section{Study Context and Theoretical Approach}

The data presented here is part of a broader, exploratory mixed methods study comprising a fully-online survey, and series of online and offline focus groups, to explore motivators that determine participation and abstention from School Strike events. As a theoretical basis, the study used an explanatory sequential design method (Ivankova et al., 2006) by first deploying a quantitative survey and then delving deeper into emerging themes via a series of focus groups. Here, we qualitatively explore a sub-section of each of these methods, specifically open-ended questions from the survey and focus groups to the effect of "Why did you participate (or not participate) in a School Strike event?" (Table 1).

The primary target group for this study was Australian prevoters. Young people have been described in literature in a variety of ways, but categories such as 'young adult' or 'child' are not "natural objects or categories" (Bessant, 2020, p. 225). These various descriptions have included: pragmatic approaches, related to the organisation of a persons' schooling or welfare (Mizen, 2004; as cited in Collin, 2015); developmental stages (Nilan et al., 2007); or simply an age group, such as between age 14 and 25 (see, for example, Collin, 2008). Manning and Edwards (2014) note that young people occupy a grey area between child and adult, and the attendees of the School Strike movement certainly fall into this area. Therefore, this study focuses on the 'pre-voting citizen', 'pre-voter' or "pre-citizen" (Harris et al., 2007, p. 19) as a way of capturing late-teens that are approaching the age in which they become democratic citizens in the country of the study, Australia. This narrows the pool of participants to roughly 16-19-year-old's, without linking them directly to a developmental or education level boundaries that can be exclusionary in studies concerning youth political participation.

\section{Survey Methods}

As the responses explored here are part of a broader study exploring factors that influence participation in the School Strike movement, the survey was first run as a pilot with undergraduate university students in February of 2020. The primary purpose of the pilot study was to ensure clarity in the survey instrument, as this stage can help to refine both content and procedures of the broader study (Yin, 2003). Target participants at this stage were undergraduate students of the author's university, Australian National University, as geographic proximity and access can play a large role in selection of the pilot case (Yin, 2003). For ethical considerations, all pilot participants were over the age of 18 (the age of consent in Australia), with the majority in either their first or second year of university studies. Participants were recruited via first year lectures, as well as online calls-for-participants on an unofficial student Facebook group.

Following the pilot, larger studies in this area have had success engaging participants via schools (see, for example, Brügger et al., 2020; Harker-Schuch et al., 2020). For this study, several jurisdictions were approached to access public schools for survey and focus group participation, with application processes spanning from mid-2019 to early-2020. However, by early-2020, the COVID-19 pandemic saw schools across the world either closing or under excessive outside pressures. It was then deemed ethically inappropriate to continue engaging schools and Education Departments to participate in the study, and recruitment was shifted fully online.

Calls for participants were placed on Twitter and Facebook, targeting demographics specific to the study through purposive sampling (see Flick, 2018). As purposive sampling targets groups or individuals with sufficient knowledge of the topic (Etikan et al., 2016), it was deemed appropriate to target teenagers and nonvoters through a number Facebook groups and pages where knowledge of the School Strike movement was likely. These targeted groups and pages included: undergraduate university student groups; climate change and School Strike groups; a range of political groups, such as those aligned with left/progressive, centrist, and right wing political stances; and parenting or home schooling groups, with a request for parents to pass on the survey to their high-school aged teenagers. These demographics were chosen as having the closest alignment with young people who have heard of the School Strike movement, and made decisions to attend or not attend an event. Due to the purposeful nature of this sampling, the data presented is likely to exclude those that are not politically or environmentally engaged in some manner. This reflects a similar approach to other studies that have focused on participation and non-participation among sympathizers of a cause, rather than a random general population sample (see Stuart et al., 2018).

The survey opened with the following questions:

1. Have you heard about the School Strike 4 Climate?

2. Have you attended a School Strike 4 Climate event? (If yes, how many) 
TABLE 2 | Difference in demographics information collected at pilot and full-scale stages of survey deployment.

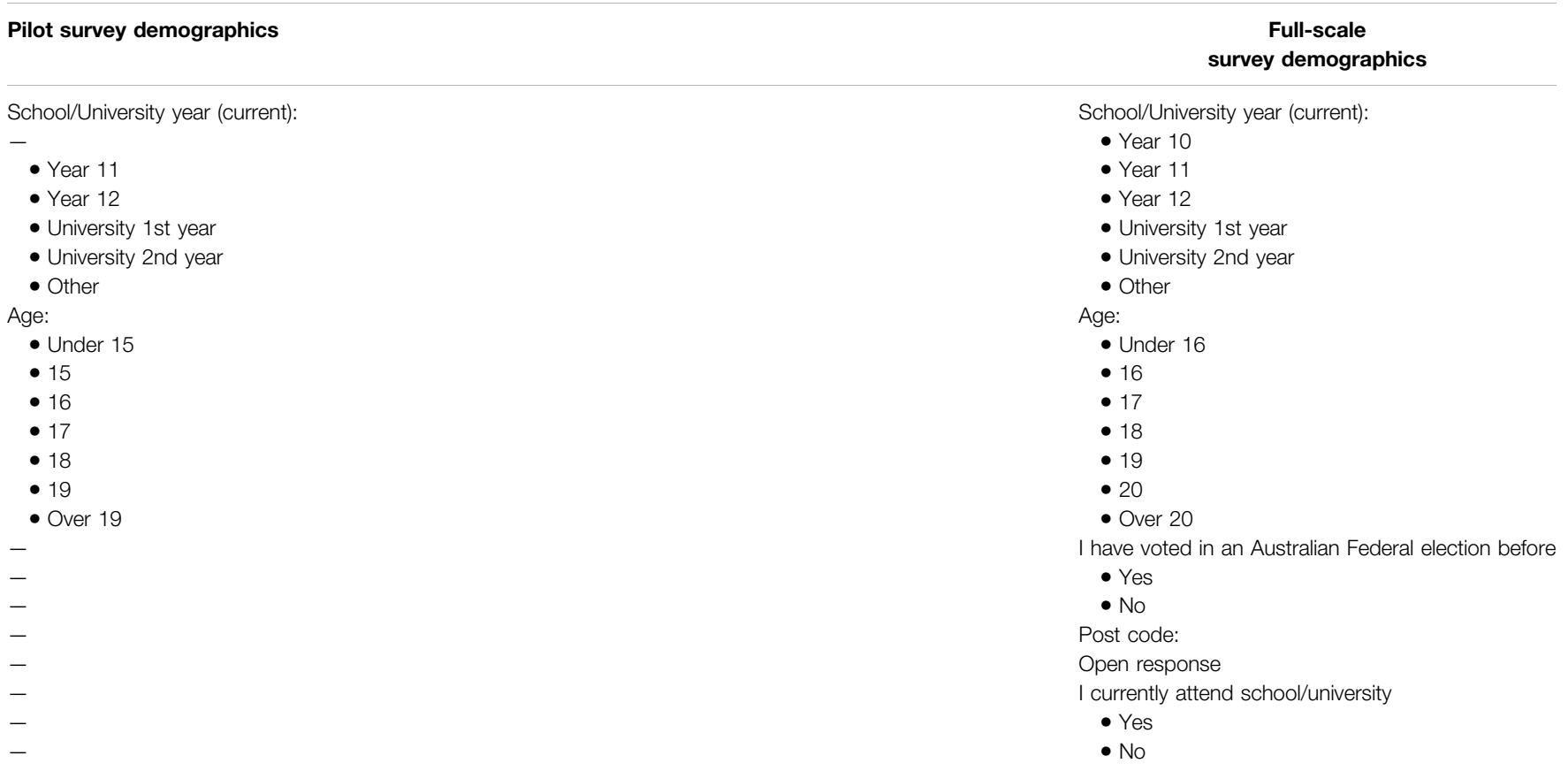

3. What was your main reason for attending/not attending a School Strike 4 Climate event?

The key to these questions is the deliberately open nature of question three (3). Open questions have a number of benefits over closed responses, such as avoiding closed question alternatives influencing the respondent's description of their thoughts (Schuman and Presser, 1979). They can also form a basis for further targeted lines of questioning by capturing a full range of possible responses (Singer and Couper, 2017). Given this research is exploratory, these results may in future serve to form the basis for more closed survey responses, but in this instance the open format was more appropriate than closed.

These questions remained unchanged between the pilot study and full scale survey, and hence data from pilot responses to these questions are also included in the analysis here. Table 2 shows the only differences between the data sets used here, where the fullscale study included a broader range of demographics information.

\section{Focus Group Methods}

Six focus groups took place in total for this research, two as part of the pilot study, plus two online and two in person (at a senior high school) as part of the full-scale study. Significant changes were made to the overall instrument after the pilot. Hence, the data here is only from full deployment of the instrument, and the pilot data has been excluded.

Distribution of the non-pilot survey included an option for respondents to indicate interest in participating in a follow up focus group. All respondents that left a contact email address were contacted with sign up information for focus groups, however none attended a focus group. Despite this, two focus group participants disclosed that they also participated in the survey portion of this research, though they were not recruited to focus groups through the survey itself.

All participants that attended an online focus group were recruited directly through social media or were referred by someone in their network. This study also used purposive sampling (Flick, 2018) to recruit participants. Similar to the survey, teenagers of school age were specifically targeted to participate in the study.

To this end, schools were approached to participate in the study, as this stage of the research occurred after schools had returned to on-campus teaching in the Australian Capital Territory, Australia. Hence, two focus groups took place at a non-government secondary school in Canberra, Australia. The school was one of several cold-called institutions, and the author had no prior affiliation with the school. Students from across multiple year levels indicated that they knew one another, but were not in the one social circle.

Across all focus groups, participants were categorized as part of a "primary selection" (Morse, 1998, p. 73, as cited in Flick, 2018) process. That is, each participant was knowledgeable about the topics, able to articulate their thoughts and reflections, and had time and willingness to participate in the study (Morse, 1998, as cited in Flick, 2018). Therefore all participants were integrated into the final analysis.

Overall, focus groups ran for between 60 and $90 \mathrm{~min}$, and were audio and video recorded. Transcriptions of focus groups were created by a combination of manual transcription and through use of Otter.AI, an artificial intelligence and machine learning software for automatically transcribing audio (About Otter, 2021). Participants were able to choose their own pseudonyms for the discussions, and these are reflected in the transcripts. 
Questions examined here are sub-sections of the full focus group discussions, focusing only on conversation generated by the specific prompts in Table 1.

In addition to asking participants to reflect on their own motivators for attending a Strike event, participants were also asked to reflect on why others may be attending. This style of projective questioning, or "Most People Projective Questions" (Ostapczuk and Musch, 2011, p. 399), is used in cases where participants may be hesitant to share their own feelings on a topic, where those feelings might be perceived as undesirable by others (Ostapczuk and Musch, 2011). Given that the target age group of 16-19-year-old's can be influenced by peers in their behaviors and beliefs (see, for example, Gaviria and Raphael, 2001) and environmental behaviors (Duarte et al., 2017), this style of questioning allows participants the freedom to explore responses to questions without the vulnerability of sharing their own inner feelings. This style of projection questioning also ensured that those who had not attended a Strike (or vice versa) were given a place to contribute their context without having personal experience.

Despite these measures, students participating in on-campus focus groups were nominated by teaching staff to participate, and these students were largely associated with the campus environment collective. Therefore, there may be present an element of social desirability bias (see Krumpal, 2013) in the way in which students responded to focus group questions, particularly with respect to reasons for non-participation. The full range of on-campus perspectives on School Strike participation and non-participation may also be limited by the selected students, as environment collective members are likely to be already engaged in pro-environmental behaviors and may be over representing this viewpoint. Similarly, five of the online focus group participants disclosed some measure of close involvement with School Strike 4 Climate events, also suggesting an over representation of environmentally engaged participants in online focus groups.

\section{Data Refinement}

In total, 107 responses were recorded for the pilot survey. Of these, 66 responses were excluded from the analysis, resulting in an analyzed pilot sample of 41 responses. These exclusions included any respondents that: were incomplete $(n=28)$; did not specify an age or university level $(n=8)$; specified an age over 19 years, but did not specify first or second year of university $(n=$ $29)$; were under the age of $18(n=1)$. Respondents that specified they were over 19 years of age but still in first $(n=2)$ or second year of university $(n=9)$ were included in the analysis, as was one respondent that specified second year university but no age $(n=$ $1)$. These inclusions were on the basis that both teenagers at school and young adults at university are both within the category of "emerging adult" (Furlong, 2017, p.36), and the common experience of early university years situates them at the same point in social development and career trajectory (for more on milestones in emerging adulthood, see Furlong, 2017). All other respondents that specified age 18 or 19 were included $(n=29)$.

In the full survey deployment, 248 survey responses were gathered. Of these, any surveys with less than $10 \%$ completion were immediately excluded $(n=77)$, as not enough information was gathered from these respondents to determine their demographics. Any respondents that did not agree to the conditions and terms of the study were also excluded $(n=2)$. Voting in Australia is compulsory for those 18 years and over at the time of an election. Therefore, respondents that declared they had voted in a federal Australian election were also excluded $(n=$ 32 ), as the study focused primarily on the category of pre-voting teenagers, or those that had not formally engaged with civic activity such as compulsory voting. Any respondents that were under the age of $16(n=4)$ were also excluded from the analysis due to ethical considerations of consent, as were those that did not specify an age and indicated they had not yet voted $(n=2)$, given that there is no way of knowing if these respondents were over 16-years-old.

Overall, analysis was done with 16-19+ year olds that had not voted in an Australian federal election, with the exception of some pilot respondents $(n=11)$ whom specified early university education level, but who's voting history is unknown, as previously mentioned. Of the total 354 recorded responses, 172 were included for analysis, and the full description of these responses can be found in Table 3.

Focus group data were limited to sections of transcripts specifically focusing on responses to the following prompts:

- Why do you think that people go to a School Strike for Climate event?

- Why do you think people do not go to a School Strike for Climate event?

- It has been reported via various media that students only attend in order to get a day off school. Could you reflect on that comment? What do you think of this?

Students in the pilot study were predominantly from the Australian National University in Canberra, thus despite their geographic information not being collected, they have been coded as Australian Capital Territory (where the campus is located) students. Similarly, the pilot study respondents were not asked if they had previously participated in an electoral voting process, and are all counted as 'unknown' in this case. Focus group participants were also not asked about their participation in voting, though as the age of voting in Australia is 18 and the focus groups took place more than 12 months after the most recent election, any participants aged 18 and under were assumed not to have voted in an election, and were coded as such.

\section{Analysis Method}

Following methods outlined by Chun et al. (2019), this research used a grounded theory approach, where after purposive sampling and early thematic exploration during the pilot study phase, key themes were coded and categorized. Initial coding followed an 'open code' approach, generating multiple provisional themes as they emerged from the data (Charmaz, 2006), and grouping them under key themes, which were generated in relation to key literature surrounding protest motivation including social themes, efficacy, or practical barriers to attendance at a Strike. Sub-categories were generated under these themes and remained unchanged once 
TABLE 3 | Full overview of study respondents by demographic information, voting status, and whether they have attended a School Strike.

\begin{tabular}{|c|c|c|c|c|}
\hline Characteristic & $\begin{array}{c}\text { Number (percent), pilot } \\
\text { survey } n=41\end{array}$ & $\begin{array}{c}\text { Number (percent), full } \\
\text { survey } n=131\end{array}$ & $\begin{array}{l}\text { Number (percent), focus } \\
\text { group participants } n=21\end{array}$ & $\begin{array}{c}\text { Number (percent), full } \\
\text { sample } n=193\end{array}$ \\
\hline \multicolumn{5}{|c|}{ Have attended a Climate Strike event } \\
\hline Yes & $21(51.2)$ & $63(48.1)$ & $11(52.4)$ & $95(49.2)$ \\
\hline No & $20(48.8)$ & $59(45)$ & $10(47.6)$ & $89(46.1)$ \\
\hline Have not heard of SS4C & $0(0)$ & $9(6.9)$ & $0(0)$ & $9(4.7)$ \\
\hline \multicolumn{5}{|l|}{ Gender } \\
\hline Female & $29(70.7)$ & $89(67.9)$ & $14(66.7)$ & $132(68.4)$ \\
\hline Male & $10(24.4)$ & $28(21.4)$ & $2(9.5)$ & $40(20.7)$ \\
\hline Gender diverse & $1(2.4)$ & $5(3.8)$ & $0(0)$ & $6(3.1)$ \\
\hline Not disclosed & $1(2.4)$ & $9(6.9)$ & $5(23.8)$ & $15(7.8)$ \\
\hline \multicolumn{5}{|l|}{ Age } \\
\hline Under 16 & $0(0)$ & $0(0)$ & $3(14.3)$ & $3(1.6)$ \\
\hline 16 & $0(0)$ & $35(26.7)$ & $4(19)$ & $39(20.2)$ \\
\hline 17 & $0(0)$ & $35(26.7)$ & $6(28.6)$ & $41(21.2)$ \\
\hline 18 & 8 (19.5) & 47 (35.9) & 7 (33.3) & $62(32.1)$ \\
\hline 19 & $21(51.2)$ & 7 (5.3) & $1(4.8)$ & $29(15)$ \\
\hline Over 19 & $11(26.8)$ & $5(3.8)$ & $0(0)$ & $16(8.3)$ \\
\hline Unknown & $1(2.4)$ & $2(1.5)$ & $0(0)$ & $3(1.6)$ \\
\hline \multicolumn{5}{|l|}{ Current school year } \\
\hline High school year 9 & $0(0)$ & $0(0)$ & $1(4.8)$ & $1(0.5)$ \\
\hline High school year 10 & $0(0)$ & $16(12.2)$ & $2(9.5)$ & $18(9.3)$ \\
\hline High school year 11 & $0(0)$ & $24(18.3)$ & $8(38.1)$ & $32(16.6)$ \\
\hline High school year 12 & $0(0)$ & $28(21.4)$ & $8(38.1)$ & $36(18.7)$ \\
\hline University year 1 & $21(51.2)$ & $49(37.4)$ & $2(9.5)$ & $72(37.3)$ \\
\hline University year 2 & $20(48.8)$ & $1(0.8)$ & $0(0)$ & $21(10.9)$ \\
\hline Not in school/uni & $0(0)$ & $6(4.6)$ & $0(0)$ & $6(3.1)$ \\
\hline Unknown & $0(0)$ & 7 (5.3) & $0(0)$ & 7 (3.6) \\
\hline \multicolumn{5}{|c|}{ Have participated in election voting } \\
\hline Yes & $0(0)$ & $0(0)$ & $0(0)$ & $0(0)$ \\
\hline No & $0(0)$ & $131(100)$ & $20(95.2)$ & $151(78.2)$ \\
\hline Unknown & $41(100)$ & $0(0)$ & $1(4.8)$ & $42(21.8)$ \\
\hline \multicolumn{5}{|l|}{ State/Territory } \\
\hline ACT & $40(97.6)$ & $37(28.2)$ & $14(66.7)$ & $91(47.2)$ \\
\hline NSW & $0(0)$ & $35(26.7)$ & $1(4.8)$ & $36(18.7)$ \\
\hline QLD & $0(0)$ & $8(6.1)$ & $0(0)$ & $8(4.1)$ \\
\hline SA & $0(0)$ & $7(5.3)$ & $0(0)$ & 7 (3.6) \\
\hline TAS & $0(0)$ & $3(2.3)$ & $3(14.3)$ & $6(3.1)$ \\
\hline VIC & $0(0)$ & $26(19.8)$ & $3(14.3)$ & $29(15)$ \\
\hline WA & $0(0)$ & $10(7.6)$ & $0(0)$ & $10(5.2)$ \\
\hline Unknown & $1(2.4)$ & $5(3.8)$ & $0(0)$ & $6(3.1)$ \\
\hline
\end{tabular}

TABLE 4 | Examples of two responses that were co-coded to multiple themes.

Data sample

Emergent code co-occurrences

"I wasn't really involved in any groups that were planning to strike so I didn't know about it until it happened. Also no one from

- No knowledge of event

my school really did it".

- Social: Peer influence

"My thought process was just like, oh, I don't really know if it's allowed, like, are we allowed to go? Am I going to have to have an absence (recorded) ? Or can I, like explain it? Because, you know, you can only have a certain number of (unexplained) absences in college. So it's like, am I going to have an absence, how many do I already have? And then I was like, well, I have schoolwork, anyway, you know, and then I'm like, one person not going isn't going to impact it. It all just stacks up.

- Social: School administration

- Unavailable: School commitment

- Low efficacy: Individual saturation in codes became apparent (no new codes introduced to explain data) (Birks and Mills, 2015). This method was applied to all short answer responses from collected surveys as well as focus group transcripts, and codes remained unchanged between data types.

Some statements were co-coded to two or more themes. Two examples of code co-occurrences can be seen in Table 4, where a survey response and focus group passage (each discussing protest non-attendance) are coded to several themes each.

\section{RESULTS}

\section{Introduction}

Overall, 41 respondents were analyzed from the pilot survey, 131 from the full distribution of the survey, and 21 participants from four focus groups (Table 3). Across the samples, there was an overrepresentation of female respondents, totaling close to $70 \%$ of the full sample. Around equal numbers of respondents were in 
TABLE 5 | Key themes that emerged as motivators to attend a protest, by code and data type.

\begin{tabular}{|c|c|c|c|}
\hline Theme & $\begin{array}{c}\text { Pilot occurrences } \\
n=21 \text { (percent sample) }\end{array}$ & $\begin{array}{c}\text { Survey occurrences } \\
n=63 \text { (percent sample) }\end{array}$ & $\begin{array}{l}\text { Focus group occurrences } \\
\text { (unique sources) }\end{array}$ \\
\hline Climate change & $8(38.1)$ & $23(36.5)$ & $9(7)$ \\
\hline Political pressure & $5(23.8)$ & $20(31.7)$ & $4(4)$ \\
\hline Movement support & $5(23.8)$ & $14(22.2)$ & $6(7)$ \\
\hline Concern for future & $2(9.5)$ & $15(23.8)$ & $7(5)$ \\
\hline Youth voice & $2(9.5)$ & $5(7.9)$ & $13(11)$ \\
\hline Social & $1(4.8)$ & $5(7.9)$ & $9(5)$ \\
\hline Personal responsibility & $0(0)$ & $6(9.5)$ & $0(0)$ \\
\hline Emotional (e.g. anger, frustration, excitement) & $0(0)$ & $2(3.2)$ & $6(5)$ \\
\hline Greta thunberg & $0(0)$ & $1(1.6)$ & $0(0)$ \\
\hline Other "greater good" sentiment & $2(9.5)$ & $5(7.9)$ & $0(0)$ \\
\hline
\end{tabular}

high school or early year university, and most common age as 18 years old. All respondents were either known to have not voted in an election (which is compulsory in Australia over the age of 18), or their electoral participation was unknown. Approximately half of the sample had attended at least one School Strike event (49.2\%), while the remainder had not $(46.1 \%)$ or had not heard of the School Strike movement (4.7\%).

\section{Motivation to Attend}

In survey responses, the most common reason for attending a protest event was related to climate change, and nearly half of all respondents mentioned climate in some form. Key themes that emerged under the climate change code included references to global responsibility, climate justice, concern for the environment, and other general mentions of climate change. The frequency of these responses, along with all other recorded motivators to attend a protest, can be seen in Table 5 .

Mentions of climate change took many forms, from generic responses of "promote climate change action" (anon, 18, university first year), "climate matters!" (anon, over 19, university second year) and "passion for the environment" (anon, 17, year 11) to the more in-depth:

- "Improve awareness of the importance of climate action amongst young people" (anon, 17, year 11)

- "Belief that Australia needs to do drastically more to tackle climate change and that it is the biggest threat to our planet and our lives at the moment and into the future." (anon, 17, university first year)

- "Show my support for action on climate change in a tangible way and be a role model for younger students at school through my environment group." (anon, 19, university first year)

Young people are generally knowledgeable about climate change (Lee et al., 2020), and given the high level of engagement with pro-environmental behavior of this age group (Bentley et al., 2004), this is an unsurprising result (for more on protesting as a form of pro-environmental behaviour, see Dono et al., 2010). These responses had considerable overlap with concerns for futures theme code, with participants expressing concern for both their own futures and the futures of others.
This echoes long-standing research showing emotional associations with and concerns for climate futures of young people (for example, see Connell et al., 1999), and some respondents had strongly emotional engagements with the conception of fighting for their futures. Some were a simple "I was anxious about the climate" (anon, 18, year 12), others were more in-depth:

- "I am sick of the govt not listening to what we want, we are Australian citizens too and their decisions impact my life, the lives of those around me and the future of Australia." (anon, 17)

- "I am scared I won't have a future." (anon, 17, year 11)

- "Catastrophic future effects climate change will have on the human race, will be much worse if it's ignored. Which is what is happening with the Liberal [conservative Australian] government." (anon, 18, university first year)

Emotional responses also often had clear targets of frustrations, in the form of adult power structures. As in Holmberg and Alvinius (2019), the global youth Climate Strikes have shifted youth rebellion from distinct actors (such as parents or teachers, people in their local area) to abstract actors (such as against "the establishment, against (in)decisions, against companies", p. 88). Note the abstract actors in these two responses from school focus groups in the present study, such as the ambiguous "you" or "they", "federal government", and "Sky News":

Jess (18, year 12): I feel like... I don't know... We were so highly educated about environmental issues from a young age and then it kind of just ... I don't know, gets filtered out of us a bit. But it's good to just be like "you taught us all this stuff, and it's so clear that if we keep treating the environment the way we are it's going to die" essentially, so like... Why? Why is nothing being done? Why are we being so heavily educated but then it seems like nothing is actually being done beyond that? (then, later in the discussion)

Michael (18, year 12): To add to that, like, the government is saying that all kids should stay in school but in school we're learning about all the environmental problems and we're taught to do 
something, create change, but when we actually try, we're pushed back and (they're saying) "no, go back to school". So what's the point in telling us that we need to fix these environmental problems but then tell us "no, you can't do it"

Jess (18, year 12): Yeah, it's like they teach you to try to change the world but then when you try to, they limit you. Like it's a very paradoxical type situation.

Moderator: When you're both are talking about "they"-who are you thinking about? Who is "them"?

Dani (18, year 12): Everyone else.

(all laugh)

Jess (18, year 12): Teachers, politics, even every-

Dani (18, year 12): Adults.

(all agree)

Dani: People in power.

$\cdots$

Adam (17, year 12): I think there's a lot of people today, especially young people who do want to make a difference, like Greta Thunberg, but a lot of young people feel like they're not being listened to. Especially by the federal government at the moment. You know, if you turn on Sky News, when Greta Thunberg was really big, there was a lot of attacks on her and I think young people are deeply frustrated at the moment of the lack of-of inaction on climate change perceived threat. And if people could stand up and wave arms about it, you get a bit of publicity. And it gets the word going about in, you know, people's living rooms. And I think that's really powerful. Like I think that's why people want to go down to the protest. Not just to meet people but actually, you know, promote a conversation and promote change, I think.

Despite these heavy emphases on environmental engagement and futures, the Strikes are also a political act in Generation Z's civic repertoire. Political pressure was a key motivator mentioned across both survey groups, and this mirrors results seen from Collin et al. (2020), who also surveyed Australian Strike participants. Examples included:

- "Protesting against the government's inaction on climate change and urging them to do better" (anon, 17, year 12)

- "I want government action on climate change and this was the main way I saw as making that happen." (anon, 18, university first year)

- "I disagree with the current climate policy and want to contribute to a political change to stop the climate crisis" (anon, over 19)

Finally, as movement support is a key predictor of mobilization potential (Klandermans and Oegema, 1987; van Stekelenburg and Klandermans, 2013), there was also a notable number of generic and specific statements of movement support, such as "To raise awareness and hopefully help to gain momentum in the movement to create a legislative change?' (anon, 16, year 11).

In focus groups, key themes emerged in parallel and similar forms to those of surveys. However, the most striking emergent theme was around pathways for providing a youth voice through the protest movement, indicating strong political efficacy for those that attended protests. Hermione, 18-year-old university first year student in Canberra, said this of the power of the movement:

Hermione: I just thought, for me, I had always been taught about climate change and I have always cared a lot about it but it was just so much more than just the science and facts of climate change. It's also about me as a youth, I felt like I had no say in anything. Not just climate change, but anything. And I-you know, adults are always saying 'youth are so apathetic and they don't care' and it's like it's because you don't listen to us! You don't care! And so yeah, for me it was not just about climate change but actually about you know, regaining my democratic rights and actually being able to like make my voice heard for literally the first time in my life. Like, obviously I was 16 at that point, never voted, so yeah was ... It was so much more than climate change for me, it was like democracy as a whole and all of the social justice and environmental stuff that comes with that.

Other participants shared similar political frustrations, and using the protest movement as a tool to express themselves as young democratic citizens was a common theme. Lauren, 17year-old, year 11 Canberra student:

Lauren: I guess, going with a bit of a cliché. I'm only 17, like I can't vote. And yet it's like... I'm going to inherit the problem. And I feel like that's where a lot of the frustration stems from. That's what a lot of the arguments are based off, is that idea that we can't do anything. Well ... except for protest, there isn't very much that we can do as young people, and yet we're going to be the ones who have to deal with it.

Some students reflected on how the protest has enabled them to make change, citing then-Prime Minister of Australia, Scott Morrison's acknowledgement of the protest as a sign that political figures were paying attention to youth voices. Michael, 18, year 12, Canberra:

Michael: We're giving them their jobs. ... If we didn't vote for them, they wouldn't have a job in the government, so... It's a democracy. Our country is a democracy. It's based on people's voices. If they're not heard, then it's not a democracy anymore.

Moderator: Did it give you a voice?

Michael: Well yeah. Because (Scott Morrison) said 'go back to school' to all the kids. 
TABLE 6 | Key themes that emerged for non-attendees of a protest event, by code and data type.

\begin{tabular}{|c|c|c|c|}
\hline Theme & $\begin{array}{c}\text { Pilot occurrences } \\
n=20 \text { (percent sample) }\end{array}$ & $\begin{array}{c}\text { Survey occurrences } \\
n=59 \text { (percent sample) }\end{array}$ & $\begin{array}{l}\text { Focus group occurrences } \\
\text { (unique sources) }\end{array}$ \\
\hline Unavailable & $12(60)$ & $34(57.6)$ & $6(8)$ \\
\hline School commitment & $2(10)$ & $22(37.3)$ & $5(7)$ \\
\hline Work commitment & $4(20)$ & $1(1.7)$ & $1(1)$ \\
\hline Other/Unspecified & $6(30)$ & $10(16.9)$ & $0(0)$ \\
\hline Disagree with the event & $6(30)$ & $5(8.5)$ & $0(0)$ \\
\hline Low efficacy & $3(15)$ & $3(5.1)$ & $8(5)$ \\
\hline Participative & $0(0)$ & $1(1.7)$ & $4(4)$ \\
\hline Protest & $3(15)$ & $2(3.4)$ & $4(3)$ \\
\hline Social factors & $0(0)$ & $6(10.2)$ & $17(11)$ \\
\hline School administration & - & $1(1.7)$ & $8(5)$ \\
\hline Community consequences & - & $0(0)$ & $2(2)$ \\
\hline Parents & - & $2(3.4)$ & $5(5)$ \\
\hline Peer (pressure to not attend or lack or support to attend) & - & $3(5.1)$ & $2(2)$ \\
\hline No/minimal knowledge of event & $0(0)$ & $7(11.9)$ & $3(5)$ \\
\hline Accessibility & $2(10)$ & $1(1.7)$ & $1(1)$ \\
\hline Apathetic & $2(10)$ & $4(6.8)$ & $1(1)$ \\
\hline Mention of climate change & $4(20)$ & $0(0)$ & $0(0)$ \\
\hline No local event & $0(0)$ & $2(3.4)$ & $0(0)$ \\
\hline Safety concerns & $0(0)$ & $1(1.7)$ & $5(5)$ \\
\hline Transport & $0(0)$ & $1(1.7)$ & $0(0)$ \\
\hline
\end{tabular}

In general, these findings are consistent with previous studies that have explored an environmentally and politically engaged youth, and contributes nuance around how young people view protest movements such as the School Strike 4 Climate as a tool in their arsenal for expressing their views on climate change.

\section{Motivation to Abstain}

Overall, participants that had not attended a protest event were most likely to have been unavailable, in disagreement with the protest events, or influenced in some way by social factors such as school administrators, parents, or peers. In general, there was far more variation between sample groups in reasons for nonattendance than reasons for attendance and all occurrences and codes for non-attendance are outlined in Table 6.

The most commonly reported reason for students not attending a protest was that they were unavailable, either with school, work, or another unspecified reason. Unspecified reasons reported in the surveys included general statements such as "I was busy", "I didn't have time" or "it clashed with other commitments". Overwhelmingly, however, most respondents indicated that they were prioritizing schoolwork over attendance at a protest event. In fact, some respondents in focus groups indicated that school is not only preferable, but that the personal consequences of leaving outweighs desire to attend a protest:

Dani (18, year 12): I just didn't go because I wanted to do my schoolwork. I do want to learn. Like I do come to school because I do want to learn and like I mean, a lot of times they're like "they just want a day off school". But to be honest, I think a lot of my friends that I talked to you just didn't go because they were like I have work to do today. I need to be in class. I don't understand this concept like... I would love to go, but I do actually want to be at school.
Jess (18, year 12): It punishes you by going because you then have to catch up on this maths class, this maths class, this chem class, this chem class, this chem class. It obviously depends if you're, like, academically motivated, I guess. But like a lot of kids are, and so by going, it's kind of like being inconvenient to yourself.

Sophie (16, year 11): September is like one of the busiest school months. And that's when the national one is, so by going you're kind of digging yourself a hole. So you kinda want to be there but... There's going to be not just actual punishment consequences, but you just falling behind. Yeah, if you're going, you want to be there.

This theme was consistent across survey and focus group responses. In contrast, a visible difference between groups was the way in which participants spoke about social factors influencing non-attendance. From this theme emerged several subthemes, and while no pilot study respondents mentioned these at all, nearly $20 \%$ of all full survey respondents mentioned at least one. These subthemes (plus examples) were:

- School administration: "very strict high school attendance policies" (anon, 18, university first year)

- Parents: "because my parents aren't comfortable with me attending strikes that have the possibility that it would get out of hand" (anon, 17, year 12)

- Peers (pressure to not attend or lack or support to attend): "Nobody to go with" (anon, 18, not in school), and "no one from my school really did it" (anon, 17, university first year)

Focus groups had in depth discussions about the extent to which each of these factors influenced participation. School community in particular was spoken of with suspicion, where 
students implied that school administrators had deliberately made attempts to circumvent protest attendance by either scheduling events on the same day, threatening consequences, or blocking information getting to students:

Asha (16, year 11): they scheduled a practice [exam] on that day, I'm not sure if that was intentional or not. I kind of get the feeling that it was.

Lara (16, year 11): [A neighboring school] scheduled their [school dance] nearby and they said if they go [to the protest] they can't go to the [school dance]. This is last year, I think.... So, I think not many girls went.

$\cdots$

Lara: I think that unless you go looking for the information, you're rarely gonna find it, like you might see a poster in [the CBD]. And that's kind of it. I think that information is just not communicated to everybody consistently.

(all agree)

Jill (17, year 11): It's not very advertised.

Asha: Yeah. And if it is, like we were saying, the posters get taken down [at school, by the administration].

(others agree)

Asha: Yeah. Like, people are trying to get rid of it. Stop the information from getting to people.

In another example of focus group discussion on social factors, students spoke of parental influence, though rarely did students mention an opposition to climate action as reasoning for parental hesitation:

Maya (16, year 11): I did want to go. My parents-my mom, specifically, wasn't too impressed about me skipping a day of school, I guess. Just like more that idea. And especially I guess for people our age, because I couldn't drive, and I live a fair way (away from the protest) as well. So like just trying to organize my way (to the protest) would be a bit difficult. That's probably the main factor.

Jenny (17, year 11): Oh, yeah. My mom would not-. Honestly, I wanted to go but I just knew it wasn't a thing. I just couldn't really ask because I already knew the answer. It was like just an assumption. Like, well, that's just not something I would be allowed to go to. And especially since we had a test on. I would just not be, you know, it would not really be an option for me. But definitely in the future. Definitely.

Many of these responses speak directly to adult structures of governance in young people's lives. Research has shown that communities of support or opposition of protest participation can influence non-participation (see, for example, Hensby, 2017), and it is possible that this extends to adult structures in which young people are deciding to participate or not.
Some participants directly addressed a feeling of low political power when it came to School Strike demonstrations, which may contribute to non-attendance. This was particularly evident when focus groups were asked to reflect on the popular notion that some attendees may be simply participating to skip school. Predominantly, discussion of this idea garnered two major responses: that it was patronizing to insinuate students had no other reasons to attend the protests, and that if there are students that use the Strike as an excuse to leave school, these students do not attend a Strike event. Adam (17, year 12, Canberra) highlighted that political power was low among teenagers, and that this was being weaponized against protestors in a patronizing way:

Adam: I found (the response) from the government, particularly the Prime Minister going 'Oooh you know those kids should go back to school because that's where they belong', you know... I found that a bit disingenuous. And kind of a bit arrogant. Coming from the Prime Minister going 'Oooh they can't vote (yet) so', you know, 'we don't have to listen to them'”

This lack of political efficacy relates to many efficacious reasons why respondents had not participated in a protest event. Efficacy in this instance was split into two broad categories:

1. Protest efficacy: the belief that as a group, protests can achieve their desired outcomes;

2. Participative efficacy: that one's individual contributions will make a difference to the group or collective of activists (van Zomeren et al., 2013).

A lack of protest efficacy was evident across both survey and focus group responses, from general statements such as "I feel like it wouldn't do much for actually changing policy" and "Don't think they work" through to more in depth examples:

- "The net payoff for me attending the strike will be significantly lower than anything else I could be doing with my time, in large because I don't believe it will effect (sic) government policy or the rate of climate change" (anon, 19, university second year)

- "They were for sure, aware of (climate change) and concerned about it. But the strike format, they were just like, well, politicians are just not going to pay any attention. It's not a vote. They're not gonna win voters by supporting it. Most likely. They're conservative politicians. They're just gonna keep being conservative." (Tad, 18, year 12)

Participative efficacy, on the other hand, was slightly less prevalent in surveys, as compared to focus groups. For example, Grace, 17-year-old year 12 student in Canberra, said this of her reasoning to not attend:

Grace: Personally, I didn't go because like, I feel like it wouldn't make a difference if I went or not. And I could make more difference, like working hard in school and 
trying to like get a job where I can influence them more directly. Yeah, like. I felt like I wouldn't be heard if I went.

Finally, while a lack of efficacy seemed an issue for many respondents, 16-year-old year 11 student Maya, remained hopeful about the impacts that protests can have, despite not having been to one herself:

Maya: I think specifically, if you look at like other issues in the past, I think protests are really powerful way to show the government-Specifically for school kids who I feel like a lot of the time, we feel like we're controlled with every single part of our lives. So to show that we have this, like, passion, and we will go out of our way to prove that we want to fight for what's right, it shows that maybe they should actually start to take into account our views on the system.

This small example highlights that a lack of political efficacy is not necessarily an underlying factor in all respondents that chose not to participate in a Strike.

Finally, event disagreement was also a prominent motivator for non-participation. While efficacy refers to the outcomes of engagement with collective action, this code is distinct in that it refers more broadly to "sympathizers" (Oegema and Klandermans, 1994, p. 703) who agree with a cause and its merits, but not with the avenue through which it has been pursued. Categories that emerged under this code mirror two of three described by Stuart et al. (2018): disagreement on methods, and reluctance to associate with the protesting group. It's worth noting here that the third of Stuart et al. (2018) factors of non-participation is a loss of autonomy in a group/crowd setting. In the present study, this has instead been captured by the participative efficacy code.

On disagreement of methods, the pilot sample (predominantly early university students from a Canberra university) frequently mention centering education over protesting:

- "Don't see the point, I study environmental science but think all our problems are better solved practically with actual science. Of course it's important to speak out about such issues but I don't think it makes a huge difference apart from landing on (sic) the media as policies don't really change as a result and even the people striking are just as ignorant to their immediate impacts on the environment" (anon, 18, university first year)

- "I prefer to educate myself so that I can be more useful when stopping climate change-if I continue well with uni I can be more effective than just another face in the crowd. So I won't skip classes just to protest" * (anon, 19, university first year)

- "Busy day and large strikes aren't my thing, I research in renewables so I don't have the 'I'm not doing enough for climate change' guilt" (anon, 19, university second year)

${ }^{\star}$ Did not attend a protest, but did not give a reason why. This statement was made in open response at the end of the survey asking for any further comments.
For those that were reluctant to associate with other protestors, the focus was instead on the risks of using protest as a form of expression:

- "Concern about how the strike could make too significant a proportion of voters turn away from caring about climate action." (anon, 18, university first year)

- "Don't believe in the form of activism it promotes and the groups that are associated with it" (anon, 18, university first year)

Again, these responses are distinct from those exhibiting low efficacy, as they don't comment directly on the effectiveness of protesting on a group or individual level. Instead these responses speak to being outside a mobilization potential that agrees with both social movement goals and format (Klandermans and Oegema, 1987).

Respondents that disagreed with protest methods, listed above, were also three of four responses (across nonattendees) that specifically mentioned the environment, and each statement was co-coded as such. The final mention of environment was one 19-year-old student in first year university who stated "Ineffective, climate change is overhyped" as their reason for non-attendance. While youth 'belief' in climate change is beyond the scope of the present study, this has been explored extensively elsewhere (for example, see Stevenson et al., 2014). It is interesting to note that while political efficacy may be low among respondents, low climate efficacy (the ability to influence climate change) was not an evident theme.

Broadly speaking, reasons for non-attendance were complex and multi-layered. One student, Dani, an 18-year-old year 12 student in Canberra, summed up this complexity, stating this of her reasons for not going to a protest:

Dani: My thought process was just like, oh, I don't really know if it's allowed, like, are we allowed to go? Am I going to have to have an absence (recorded)? Or can I, like explain it? Because, you know, you can only have a certain number of (unexplained) absences in (senior high school). So it's like, am I going to have an absence, how many do I already have? And then I was like, well, I have schoolwork, anyway, you know, and then I'm like, one person not going isn't going to impact it. It all just stacks up.

\section{DISCUSSION}

This research explored motivators of teenagers to either attend or not attend a School Strike protest event, finding non-participation is motivated by a distinct set of factors separate to those that motivate participation. In general, young people attending Strikes are motivated by a concern for the climate, and see protesting as a key part of their political repertoire. Non-participants were not necessarily found to be the 'opposite' of attendees: predominantly, non-attendees were simply unavailable or prioritizing studies in favor of attending a Strike. Various levels and types of low efficacy 
(participative and protest) were also found to be key motivators to not attend a Strike, as were social factors such as pressure from adults or peers, though the latter were more prominent in schoolbased focus groups than in surveys.

For many respondents, there was not a singular clear-cut reason for attendance or non-attendance, and the way in which young people explore issues of environmental activism can be complex, intertwining many different competing priorities. We see this especially when students speak of government action and their desire for stronger action on climate change: pro-environmental positions are closely linked to political acts. While this is to be expected from the School Strike movement, it highlights how young people's political engagement is strongly tied to issues rather than political structures (Norris, 2003; Pickard, 2019), and enacted through new opportunities of participation through "issues-based networks" (Collin and Mccormack, 2019, p. 497). In the case of many respondents here, participation is not an 'either-or' proposition between an environmental or political motivator.

This research found that non-participants did not mirror participants with a direct lack of political or environmental engagement, despite non-participation often being inferred directly from participant studies. Non-participants in this study very rarely exhibited active hostility toward the movement, climate change, or engagement with politics more broadly. In opposition to the popular idea that young people use the Strike as an excuse to leave school (Barraclough, 2019; RNZ, 2021), respondents in this study highlight that staying at school or prioritizing school work is a key factor in not attending a Strike. This is consistent with work of Harris et al. (2010), who's study on Australian youth political engagement showed students top personal concerns were "getting a good job" (p. 17) and "doing well in studies" (p. 17).

Placing a high importance on schoolwork may also be indicative of structural constraints that exist for young people, as imposed by adults. Especially in focus groups, respondents were cognizant of the influence that school administrators and parents had over their ability to go to a protest. Namely, there was a concern that students would face consequences by attending a Strike, from both school administrators and family. Parents can play an important role in a young person's engagement with climate change, as they are seen as a trusted source of information (Corner et al., 2015), contributor of social norms around proenvironmental behavior (Busch et al., 2019), and can influence a young person's climate change risk perception level (Mead et al., 2012). While the specific contributions of parents on participants willingness to engage are beyond the scope of the present study, what we see here is a much more practical demonstration of parental influence. Parents may have a direct influence on the mobilization potential (Klandermans and Oegema, 1987) of young people seeking to engage in environmental activism by removing student ability to attend an event despite intention and motivation to do so.

Participants of a Strike also referred to adult influences in several instances, especially as targets of the resistance movement. These included abstract actors such as governments, news providers and more broadly 'adults'. It is clear from the framing of these comments that adults are seen as a blanket "out group" (Fielding and Hornsey, 2016, p. 2), and the results presented here support research showing a shift in youth resistance from distinct individuals to broad and complex abstract groups (Holmberg and Alvinius, 2019).

Respondents also frequently highlighted a lack of agency in political process, which, while not an overwhelmingly prominent response, did arise as a reason for non-attendance. For those wishing to engage, lack of youth voice to parliament may lead to disengagement from the system (Manning and Edwards, 2014). However, rhetorically speaking, political figures use dismissive language in order to belittle the agency of young people attending the Strikes (Feldman, 2020), such as implying young people are only attending a Strike to skip school. But this rhetorical engagement can also be seen as a positive, as reflected in comments from 18-year-old Michael, who used political acknowledgement of the Strike as a sign of movement impact. Conversely, there may be adverse consequences for young people constantly exposed to negative stereotyping from adults, incorrect or otherwise. Several focus group respondents noted that they had heard young people were attending Strikes to 'skip school' and assumed this motivation to be true of their peers. The risk here is that repeatedly being stereotyped may have a backfire effect and begin to influence young people of this age group, resulting in a self-belief of the negative stereotype (Bessant, 2020). Noting how young people speak of their agency, and respond to broader rhetoric, in adult government structures is important to consider in the broader conversation on youth political engagement.

However, structural barriers are not the only mechanisms for disengagement, and psychological processes can also play a role in a decision to step back from political acts such as protest (Stuart et al., 2018). In some cases, non-participants in this study showed a rejection of the methods or people engaged with the School Strike movement. There was a concern among rejecters of the movement that association with activists can turn other voters away from the cause, or that activists were a group to be in opposition with. However, there was no rejection of climate change action, other than one response out of all samples. This tension between being a sympathizer of a cause (Klandermans and Oegema, 1987) and not wanting to participate in the collective action due to the methods or identities of the activists strongly supports previous research in this area (see Stuart et al., 2018). Interestingly, this rejection of methods or other protest actors was evident in the survey sample, but not in the focus groups. This may point to a certain level of desirability bias (Krumpal, 2013) in the focus groups, where participants could be influenced by normative attitudes in the group that would suggest that, overall, the protest movement is a positive form of collective action.

Distinct from event agreement or disagreement, efficacious people tend to be drawn to normative actions such as protesting (Tausch et al., 2011). This may be why efficacy was an implicit underlying factor in many responses from participants who had attended Strike events. In the Tausch et al. (2011) study, however, non-efficacious people were associated with non-normative or extreme forms of activism. By contrast, a lack of efficacy in the present study was more visibly explicit in those that had decided 
not to attend a protest. Though we cannot know whether these respondents are engaging in other forms of extreme activism, we can investigate their levels of efficacy in both an individual and group sense. Efficacy was coded specifically in non-attendee responses via protest efficacy-whether these specific actions have an effect on policy-and participative efficacy-whether individual contributions will make a difference to the group action. These two codes in combination highlighted a notable absence of low political efficacy, or the sense that one's individual actions can't influence political process (Campbell et al., 1954; as cited in van Stekelenburg and Klandermans, 2013). Overall, the combination of event rejection and efficacy codes almost directly mirrored the work of Stuart et al. (2018), who found that disagreement on methods, reluctance to associate with the protesting group and a loss of autonomy in a group/crowd setting were key reasons where people decided not to participate in collective action. The present study takes this theory specifically into the realm of youth activism, finding it applicable to sympathizers much younger than those who participated in the original Stuart et al. (2018) study, which had a mean age of 32.5 years $(\mathrm{SD}=13)$.

The general consensus in the present sample that climate mitigation is a positive (or, at least, not outwardly negative) cause links strongly with the underlying finding that participants exhibited a concern for their future as a reason to participate in a Strike. This echoes the Harris et al. (2010) study mentioned previous, where "Environmental issues" (p. 18) were also a top concern for youth futures, as well as more recent studies of School Strike participants (such as Collin et al., 2020). On the theme of environmental efficacy-the ability to influence climate change in the future (see Ojala, 2012) - there was a notable absence of low environmental efficacy across responses. No respondents that mentioned climate change, whether participants at a Strike or not, were doubtful about whether they could influence the future of climate change in and of itself. This presents a hopeful view of youth climate futures, and research has found that hope can have a direct influence on young people's engagement with the environment (Ojala, 2012). However, some studies have found ambivalence toward 'negative' future scenarios, as efforts made to stave off climate change may be met with ridicule, or ignored completely (Threadgold, 2012). The present research highlights another piece of this complex interplay between hope and pessimism that youth activists will influence decision makers on climate change policy.

In this study, a range of differing themes emerged between the surveyed sample and those in focus groups, especially when investigating reasons why participants did not attend a protest. This may be due to the subtle shift in wording between the two scenarios, as the use of Most People Projective Questions (Ostapczuk and Musch, 2011) is expected to elicit different responses to direct questioning. Alternatively, the setting of peer discussion (school, or online) may be encouraging a focus on a shared social identity between students. All participants in focus groups indicated in some way support for the School Strike movement overall, such as alignment with the School Strike values, belief that the climate is at risk, and to some level personal support will enhance climate outcomes (for more on public support for environmental movements, see Stern et al., 1999). Participants may hence be demonstrating a set of subjective norms (Ajzen, 2011), and given that social norms can influence decision making with regards to climate change (Busch et al., 2019), this may explain why the focus of the group discussions was more skewed to social factors influencing Strike non-participation.

Though not the objective or intent, this study is perhaps limited by the inability to generalize more broadly to Australian students outside of this sample, as it is firmly exploratory and qualitative in nature. However, it does give an important introductory perspective on how young Australians may be engaging with environmental activism, especially in the area of non-participation. A second limitation is similar to the work of Collin et al. (2020) who state that securing appropriate surveys and consent for minors contributes to unrepresentative samples, excluding hard-to-reach groups. With the present research, sampling limitations online and in schools proved to be a major challenge in recruiting participants. In addition, the sample this study engaged may have been disproportionately environmentally motivated. Future studies may wish to further utilize Most People Projection Questioning (Ostapczuk and Musch, 2011) to explore broader social norms around barriers to protest engagement, and employ random population sampling in order to widen the research on youth activism beyond this bias. Finally, further analysis is required to ascertain the representation of regional and remote students as part of the sample. As an especially challenging group for recruitment, future research should aim to ensure a broad representation from these nonurban students.

This study forms a foundational basis to continue investigating how young people engage with, or don't engage with, environmental activism in Australia. Results here strengthen the notion that non-participation is a distinct action in and of itself, as opposed to a simple mirroring of motivators to participate in activism. Further research should continue to highlight non-participants as an integral part of understanding youth, politics, and environmental action, especially in the School Strike 4 Climate case.

\section{DATA AVAILABILITY STATEMENT}

The raw data supporting the conclusions of this article will be made available by the authors, without undue reservation.

\section{ETHICS STATEMENT}

The studies involving human participants were reviewed and approved by Australian National University Human Research Ethics Committee. Written informed consent from the participants' legal guardian/next of kin was required and obtained for under age focus group participants, and not required to participate in the survey portion of this study. This is in accordance with the national legislation and the institutional requirements. 


\section{AUTHOR CONTRIBUTIONS}

HF is sole contributor to this manuscript (includes study design, data collection, analysis, and manuscript preparation).

\section{REFERENCES}

About Otter (2021). Otter.Ai. Available at: https://otter.ai/about.

Ajzen, I. (2011). The Theory of Planned Behaviour: Reactions and Reflections. Psychol. Health 26 (9), 1113-1127. doi:10.1080/08870446.2011.613995

Andersson, E. (2015). "Situational Political Socialization: A Normative Approach to Young People's Adoption and Acquisition of Political Preferences and Skills. J. Youth Stud. 18 (8), 967-983. doi:10.1080/13676261.2015.1020926

Barraclough, C. (2019). The Truth about Australia'S Climate Change Truants. News.Com.Au. Available at: https://www.news.com.au/lifestyle/parenting/ school-life/the-truth-about-australias-climate-change-truants/news-story/ $613 \mathrm{dc} 0906024 \mathrm{c} 3 \mathrm{~d} 2 \mathrm{~b} 3 \mathrm{be} 68 \mathrm{ac} 2 \mathrm{f} 123 \mathrm{dc} 8$.

Bentley, M., Fien, J., and Neil, C. (2004). Sustainable Consumption: Young Australians as Agents of Change. Canberra: Department of Family and Community Services.

Bessant, J. (2020). From Denizen to Citizen: Contesting Representations of Young People and the Voting Age. J. Appl. Youth Stud. 3 (3), 223-240. doi:10.1007/ s43151-020-00014-4

Birks, M., and Mills, J. (2015). Grounded theory: A practical guide. London: Sage. Brügger, A., Gubler, M., Steentjes, K., and Capstick, S. B. (2020). Social Identity and Risk Perception Explain Participation in the Swiss Youth Climate Strikes. Sustainability (Switzerland) 12 (24), 1-17. doi:10.3390/su122410605

Busch, K. C., Ardoin, N., Gruehn, D., and Stevenson, K. (2019). Exploring a theoretical model of climate change action for youth. Int. J. Sci. Educ. 41 (17), 2389-2409. doi:10.1080/09500693.2019.1680903

Campbell, A., Gurin, G., and Miller, W. E. (1954). The Voter Decides. Evanston, IL: Row, Peterson.

Charmaz, K. (2006). Constructing Grounded Theory: A Practical Guide through Qualitative Analysis. London: Sage.

Chun, T., Ylona, M. B., and Francis, K. (2019). Grounded Theory Research: A Design Framework for Novice Researchers. SAGE Open Med. 7, 205031211882292. doi:10.1177/2050312118822927

Collin, P., and Mccormack, J. (2019). "Young People and Politics.," in Australian Politics and Policy: Senior Edition. Editors J. C. Peter, B. Nicholas, R. B. John, C. David, C. Ian, G. Adele, (Sydney: Sydney University Press).

Collin, P. (2015). Young Citizens and Political Participation in a Digital Society. London: Palgrave Macmillan.

Collin, P. (2008). Young People Imagining a New Democracy: Literature Review. Sydney: The Whitlam Institute within the University of Western.

Collin, P., Matthews, I., Churchill, B., and Jackson, S. (2020). "Australia," in Protest for a Future II: Composition, Mobilization and Motives of the Participants in Fridays for Future Climate Protests on 20-27 September, 2019, in 19 Cities Around the World. Editors J. de Moor, U. Katrin, W. Mattias, W. Magnus, and D. V. Michiel.

Connell, S., Fien, J., Lee, J., Sykes, H., and Yencken, D. (1999). "If it Doesn't Directly Affect You, You Don't Think about it': A Qualitative Study of Young People's Environmental Attitudes in Two Australian Cities. Environ. Educ. Res. 5 (1), 95-113. doi:10.1080/1350462990050106

Corner, A., Roberts, O., Chiari, S., Völler, S., Mayrhuber, E. S., Mandl, S., et al. (2015). How Do Young People Engage with Climate Change? the Role of Knowledge, Values, Message Framing, and Trusted Communicators. Wiley Interdiscip. Rev. Clim. Change 6 (5), 523-534. doi:10.1002/wcc.353

Dalton, R. J. (1982). The Pathways of Parental Socialization. Am. Polit. Q. 10 (2), 139-157. doi:10.1177/004478082010002001

de Moor, J., De Vydt, M., Uba, K., and Wahlström, M. (2020a). New Kids on the Block: Taking Stock of the Recent Cycle of Climate Activism. Soc. Move. Stud. 00 (00), 1-7. doi:10.1080/14742837.2020.1836617

de Moor, J., Uba, K., Wahlström, M., Wennerhag, M., and De Vydt, M. (2020b). Protest for a Future II: Composition, Mobilization and Motives of the Participants in Fridays for Future Climate Protests on 20-27 September,

\section{FUNDING}

Author receives support via an Australian Government Research Training Program (RTP) Scholarship.

2019, in 19 Cities Around the World. Available at: https://anu365-my. sharepoint.com/:b:/g/personal/u5402286_anu_edu_au/ET6Xo3EdtstDmh7_ YqIFJc4Bs8EpCzhtYrNLZpA8Uo9eBg?e=NJrKh5.

Delli, C., and Michael, X. (2000). Gen.Com: Youth, Civic Engagement, and the New Information Environment. Polit. Commun. 17 (4), 341-349. doi:10.1080/ 10584600050178942

Dono, J., Webb, J., and Richardson, B. (2010). The relationship between environmental activism, pro-environmental behaviour and social identity. J. Environ. Psychol. 30 (2), 178-186. doi:10.1016/j.jenvp.2009.11.006

Duarte, R., Escario, J. J., and Sanagustín, M. V. (2017). The Influence of the Family, the School, and the Group on the Environmental Attitudes of European Students. Environ. Educ. Res. 23 (1), 23-42. doi:10.1080/13504622.2015.1074660

Etikan, I., Musa, S. A., and Alkassim, R. S. (2016). Comparison of convenience sampling and purposive sampling. Am. J. Theor. Appl. Stat. 5 (1), 1-4. doi:10. 11648/j.ajtas.20160501.11

Feldman, H. R. (2020). A Rhetorical Perspective on Youth Environmental Activism. J. Sci. Commun. 19 (6), 1-10. doi:10.22323/2.19060307

Fielding, K. S., and Head., B. W. (2012). “Determinants of Young Australians' Environmental Actions:The Role of Responsibility Attributions, Locus of Control, Knowledge and Attitudes. Environ. Educ. Res. 18 (2), 171-186. doi:10.1080/13504622.2011.592936

Fielding, K. S., and Hornsey, M. J. (2016). A Social Identity Analysis of Climate Change and Environmental Attitudes and Behaviors: Insights and Opportunities. Front. Psychol. 7, 121. doi:10.3389/fpsyg.2016.00121

Flick, U. (2018). Designing Qualitative Research. Sage.

Furlong, A. (2017). Routledge Handbook of Youth and Young Adulthood. Second Edition. Abingdon: Routledge.

Fyfe, I. (2009). Researching Youth Political Participation in Australia: Arguments for an Expanded Focus. Youth Stud. Aust. 28 (1), 37-45.

Gaviria, A., and Raphael, S. (2001). School-based peer effects and juvenile behavior. Rev. Econ. Stat. 83, 257-268. doi:10.1162/00346530151143798

Han, H., and Ahn, S. W. (2020). Youth Mobilization to Stop Global Climate Change: Narratives and Impact. Renew. Resour. J. 34 (4), 2-12.

Harker-Schuch, I., Lade, S., Mills, F., and Colvin, R. (2020). Opinions of 12 to 13Year-Olds in Austria and Australia on the Concern, Cause and Imminence of Climate Change. Ambio 50, 644. doi:10.1007/s13280-020-01356-2

Harris, A., Wyn, J., and Younes, S. (2010). Beyond Apathetic or Activist Youth. Young 18 (1), 9-32. doi:10.1177/110330880901800103

Harris, A., Younes, S., and Wyn, J. (2007). Young People and Citizenship: An Everyday Perspective. Youth Stud. Aust. 26 (3), 19-27.

Hensby, A. (2017). Networks of non-participation: Comparing 'supportive', 'unsupportive' and 'undecided' non-participants in the UK student protests against fees and cuts. Sociology 51 (5), 957-974. doi:10.1177/0038038515608113

Holmberg, A., and Alvinius, A. (2020). Children's protest in relation to the climate emergency: A qualitative study on a new form of resistance promoting political and social change. Childhood 27 (1), 78-92. doi:10.1177/0907568219879970

Hornsey, M. J., Blackwood, L., Louis, W., Kelly, F., Mavor, K., Morton, T., et al. (2006). Why Do People Engage in Collective Action? Revisiting the Role of Perceived Effectiveness. J. Appl. Soc. Psychol. 36 (7), 1701-1722. doi:10.1111/j. 0021-9029.2006.00077.x

Ivankova, N. V., Creswell, J. W., and Stick, S. L. (2006). Using Mixed-Methods Sequential Explanatory Design: From Theory to Practice. Field Methods 18 (1), 3-20. doi:10.1177/1525822X05282260

Klandermans, B., and Oegema, D. (1987). Potentials, Networks, Motivations, and Barriers: Steps towards Participation in Social Movements. Am. Sociological Rev. 52 (4), 519-531. doi:10.2307/2095297

Klandermans, B., and Van Stekelenburg, J. (2014). Why People Don't Participate in Collective Action. J. Civil Soc. 10 (4), 341-352. doi:10.1080/17448689.2014.984974

Krumpal, I. (2013). Determinants of social desirability bias in sensitive surveys: a literature review. Qual. Quant. 47 (4), 2025-2047. doi:10.1007/s11135-011$9640-9$ 
Lee, K., Gjersoe, N., O’Neill, S., and Barnett, J. (2020). Youth Perceptions of Climate Change: A Narrative Synthesis. WIREs Clim. Change 11, 1-24. doi:10.1002/ wcc. 641

Manning, B., and Ryan, R. (2004). Youth and Citizenship. Australian Government Department of Family and Community Services on behalf of NYARS. Canberra: National Capital Printing.

Manning, N., and Edwards, K. (2014). Why Has Civic Education Failed to Increase Young People's Political Participation?. Sociological Res. Online 19 (1), 5. doi:10. 5153/sro.3206

McKnight, H. (2020). 'The Oceans Are Rising and So Are We': Exploring Utopian Discourses in the School Strike for Climate Movement. Brief Encounters 4 (1). doi:10.24134/be.v4i1.217

Mead, E., Roser-Renouf, C., Rimal, R. N., Flora, J. A., Maibach, E., and Anthony, L. (2012). Information Seeking about Global Climate Change Among Adolescents: The Role of Risk Perceptions, Efficacy Beliefs, and Parental Influences. Atlantic J. Commun. 20 (1), 31-52. doi:10.1080/15456870.2012.637027

Mizen, P. (2004). The Changing State of Youth. New York, NY: Palgrave.

Morse, J. M. (1998). Designing funded qualitative research. En: Denzin NK, Lincoln YS. Strategies of qualitative inquiry.

Nilan, P., Julian, R., and Germov, J. (2007). Australian Youth: Social and Cultural Issues. Pearson Education Australia.

Norris, P. (2003). Young People \& Political Activism: From the Politics of Loyalties to the Politics of Choice?. Counc. Europe Symp. 2003, 1-32.

Oegema, D., and Klandermans, B. (1994). Why social movement sympathizers don't participate: Erosion and nonconversion of support. Am. Sociol. Rev., 703-722.

Ojala, M. (2012). Hope and Climate Change: The Importance of Hope for Environmental Engagement Among Young People. Environ. Educ. Res. 18 (5), 625-642. doi:10.1080/13504622.2011.637157

Ostapczuk, M., and Musch, J. (2011). Estimating the Prevalence of Negative Attitudes towards People with Disability: A Comparison of Direct Questioning, Projective Questioning and Randomised Response. Disabil. Rehabil. 33 (5), 399-411. doi:10.3109/09638288.2010.492067

Partridge, E. (2008). From Ambivalence to Activism: Young People's Environmental Views and Actions. Youth Stud. Aust. 27 (2), 18-26.

Pickard, S. (2019). Politics, Protest and Young People: Political Participation and Dissent in 21st century Britain. London: Springer.

Pickard, S., and Bessant, J. (2018). Young People Re-generating Politics in Times of Crises (Palgrave Macmillan).

RNZ (2021). Climate Change Protest on School Day Divides Mps. RNZ. Available at: https://www.rnz.co.nz/news/political/384012/climate-change-protest-onschool-day-divides-mps.

Schuman, H., and Presser, S. (1979). The open and closed question. Am. Sociol. Rev., 692-712.

Singer, E., and Couper, M. P. (2017). Some methodological uses of responses to open questions and other verbatim comments in quantitative surveys. Methods Data Anal. J. Quant. Meth. Survey Methodol. 11 (2), 115-134. doi:10.12758/mda.2017.01

Solhaug, T. (2006). Knowledge and Self-Efficacy as Predictors of Political Participation and Civic Attitudes: With Relevance for Educational Practice. Pol. Futures Educ. 4 (3), 265-278. doi:10.2304/pfie.2006.4.3.265

Stern, P. C., Dietz, T., Abel, T., Guagnano, G. A., and Kalof, L. (1999). A ValueBelief-Norm Theory of Support for Social Movements: The Case of Environmentalism. Hum. Ecol. Rev. 6 (2), 81-97.
Stevenson, K. T., Nils Peterson, M., Bondell, H. D., Moore, S. E., and Carrier, S. J (2014). Overcoming Skepticism with Education: Interacting Influences of Worldview and Climate Change Knowledge on Perceived Climate Change Risk Among Adolescents. Climatic Change 126 (3-4), 293-304. doi:10.1007/ s10584-014-1228-7

Stuart, A., Thomas, E. F., and Donaghue, N. (2018). "I Don't Really Want to Be Associated with the Self-Righteous Left Extreme": Disincentives to Participation in Collective Action. J. Soc. Polit. Psychol. 6 (1), 242-270. doi:10.5964/jspp.v6i1.567

Tausch, N., Becker, J. C., Spears, R., Christ, O., Saab, R., Singh, P., et al. (2011). Explaining radical group behavior: Developing emotion and efficacy routes to normative and nonnormative collective action. J. Personal. Soc. Psychol. 101 (1), 129. doi: $10.1037 / \mathrm{a} 0022728$

Threadgold, S. (2012). 'I reckon my life will be easy, but my kids will be buggered': ambivalence in young people's positive perceptions of individual futures and their visions of environmental collapse. J. Youth Stud. 15 (1), 17-32. doi:10. 1080/13676261.2011.618490

van Stekelenburg, J., and Klandermans, B. (2013). The Social Psychology of Protest. Curr. Sociol. 61 (5-6), 886-905. doi:10.1177/0011392113479314

van Zomeren, M., Postmes, T., and Russell, S. (2008). Toward an Integrative Social Identity Model of Collective Action: A Quantitative Research Synthesis of Three Socio-Psychological Perspectives. Psychol. Bull. 134 (4), 504-535. doi:10.1037/ 0033-2909.134.4.504

van Zomeren, M., Saguy, T., and Fabian, M. H. S. (2013). Believing in "Making a Difference" to Collective Efforts: Participative Efficacy Beliefs as a Unique Predictor of Collective Action. Group Process. Intergroup Relations 16 (5), 618-634. doi:10.1177/1368430212467476

Wahlström, M., Sommer, M., Kocyba, P., de Vydt, M., De Moor, J., Davies, S., et al. (2019). Protest for a Future: Composition, Mobilization and Motives of the Participants in Fridays for Future Climate Protests on 15 March, 2019 in 13 European Cities. Keele University.

Yin, R. K. (2003). Designing Case Studies. Qual. Res. Methods 5, 359-386.

Zummo, L., Gargroetzi, E., and Garcia, A. (2020). Youth Voice on Climate Change: Using Factor Analysis to Understand the Intersection of Science, Politics, and Emotion. Environ. Educ. Res. 26 (8), 1207-1226. doi:10.1080/13504622.2020. 1771288

Conflict of Interest: The author declares that the research was conducted in the absence of any commercial or financial relationships that could be construed as a potential conflict of interest.

Publisher's Note: All claims expressed in this article are solely those of the authors and do not necessarily represent those of their affiliated organizations, or those of the publisher, the editors and the reviewers. Any product that may be evaluated in this article, or claim that may be made by its manufacturer, is not guaranteed or endorsed by the publisher.

Copyright $\odot 2021$ Feldman. This is an open-access article distributed under the terms of the Creative Commons Attribution License (CC BY). The use, distribution or reproduction in other forums is permitted, provided the original author(s) and the copyright owner(s) are credited and that the original publication in this journal is cited, in accordance with accepted academic practice. No use, distribution or reproduction is permitted which does not comply with these terms. 